\title{
ACOMPANHAMENTO TERAPÊUTICO NA PROPOSTA DE ALTA-ASSISTIDA IMPLEMENTADA EM HOSPITAL PSIQUIÁTRICO: RELATO DE UMA EXPERIÊNCIA ${ }^{1}$
}

\author{
Cintia Guedes Bezerra* \\ Magda Dimenstein**
}

\section{RESUMO}

A Alta-Assistida/AA e o Acompanhamento Terapêutico/AT são práticas que se inserem no contexto atual da atenção à saúde mental em concordância com as diretrizes que norteiam a Reforma Psiquiátrica. Atualmente, vive-se o desafio da reintegração social de sujeitos portadores de transtornos mentais, uma vez que ainda não se dispõe de uma rede ágil, flexível e resolutiva para atendê-los. A proposta de uma saída do hospital planejada e assistida é, pois, uma estratégia fundamental no processo de desinstitucionalização. Este trabalho objetiva apresentar uma experiência de AT realizada junto a um paciente do Hospital Dr. João Machado, em Natal, e discutir os efeitos e resultados desta forma de atenção na proposta de alta-assistida aí implementada.

Palavras-chave: saúde mental; reforma psiquiátrica; alta-assistida; acompanhamento terapêutico; reinserção social.

\section{Abstract \\ THERAPEUTIC ACCOMPANIMENT IN THE PROPOSAL OF ASSISTED DISCHARGE IMPLEMENTED IN A PSYCHIATRIC HOSPITAL: REPORT OF AN EXPERIENCE \\ Assisted Discharge/AD and Therapeutic Accompaniment/TA are practices that are inserted in the present context of attention to mental health in accordance with the directives that guide}

* Aluna do curso de Graduação em Psicologia da Universidade Federal do Rio Grande do Norte (UFRN) e Bolsista de IC/PBIC-CNPq.

** Doutora em Saúde Mental pela Universidade Federal do Rio de Janeiro (UFRJ); Professora do Departamento de Psicologia da Universidade Federal do Rio Grande do Norte (UFRN); Pesquisadora do CNPq. 
Psychiatric Reforms. Nowadays, people with a mental upset live the challenge of social reintegration, since there isn't available a flexible, agile and firm network capable of helping them. The proposal of a planned and watched exit of the hospital is, therefore, a primary strategy in the process of de-institutionalization. This work intends to present an experience of TA carried out with a patient from the Dr. João Machado Hospital, in the city of Natal, and discuss the effects and results of this form of attention in the proposal of assisted discharge that was applied.

Keywords: mental health; psychiatric reform; assisted discharge; therapeutic accompaniment; social reintegration.

\section{INTRODUÇÃO}

As práticas que são alvo de discussão neste trabalho, quais sejam, a AltaAssistida e o Acompanhamento Terapêutico, inserem-se na atenção à saúde mental em concordância com a proposta da Reforma Psiquiátrica de promover a reinserção social do paciente portador de transtorno mental, o qual, antes de possuir qualquer diagnóstico, é um sujeito com nome, desejo, história e direito de exercício de cidadania. Na história da saúde mental, esses sujeitos têm sido marginalizados e excluídos do convívio na sociedade por apresentarem um diferente modo de ser/estar no mundo, que é rejeitado e desconsiderado, posto que vai de encontro às formas de existir padronizadas e concebidas pela maioria da população como normais.

No século XVII, surgiram os primeiros depósitos humanos, os asilos. Considerava-se necessário isolar os "loucos" - pobres, negros, indigentes ou a pessoa considerada "fora da razão" e, portanto, perigosa - para proteger a sociedade. No Brasil, em 1852, a exclusão é oficializada com a criação do primeiro hospício D. Pedro II, no Rio de Janeiro, o qual surge com uma vocação: a da higienização. Neste momento inicial se faziam fortemente presentes os maus-tratos e a ausência de um tratamento terapêutico, já que a loucura não tinha adquirido ainda o status de doença, o que ocorreu posteriormente através da influência europeia, principalmente francesa, em que, em fins do século XVIII, o médico Philippe Pinel conferiu à loucura a qualidade de doença, tornando-a objeto da nova especialidade médica, a psiquiatria. Pinel inaugura uma longa tradição terapêutica que permanece até hoje: o tratamento moral e o isolamento do mundo exterior com a hospitalização. Esse tratamento se caracterizava por ser de cunho moral, corretivo e reeducador.

A ideia de alienação mental, que pressupunha estar fora da realidade e a ausência de responsabilização pelos próprios atos, produziu o medo e as atitudes 
de segregação e exclusão em relação àqueles considerados perigosos. $\mathrm{O}$ manicômio então ganhou respaldo científico e social, tornando-se umas das instituiçôes mais consagradas até a atualidade, principalmente até a II ${ }^{\mathrm{a}}$ Guerra Mundial, quando surgiram inúmeros movimentos de crítica ao Hospital Psiquiátrico pelo seu caráter ineficaz, segregador e iatrogênico. Apontavam para a necessidade de uma reforma e se aglutinavam em dois vetores principais, a saber: a desconstrução do modelo hospitalocêntrico ou desospitalização, representada pela Psiquiatria Comunitária Americana e Psicoterapia Institucional Francesa, e a expansão de uma nova proposta, a de desinstitucionalização, como uma prática que vai além da questão técnica e administrativa do simplesmente "fazer", produtora de uma outra realidade e cultura, concebida pela Psiquiatria Democrática Italiana, liderada pelo médico psiquiatra Franco Basaglia.

No Brasil, no fim dos anos 1970 e início dos anos 1980, surge um momento de crítica ao modelo, até então vigente, de exclusão do portador de transtorno mental, corroborando com os anseios pela reforma da assistência psiquiátrica nacional. Em 1978, constitui-se o Movimento dos Trabalhadores em Saúde Mental (MTSM) que, segundo Amarante (1996), caracteriza-se como o mais importante acontecimento no contexto da reforma no campo de saúde mental, introduzindo a estratégia da desinstitucionalização no âmbito das políticas públicas. Diferentemente das propostas anteriores da década de 60 que se referiam exclusivamente a transformaçôes técnicas, o projeto do MTSM apresenta como marca a crítica ao saber psiquiátrico.

A influência europeia, principalmente do modelo italiano de Basaglia, reverberou posteriormente no Brasil, nos últimos anos da década de 80 , com a reconstrução do conceito de desinstitucionalização, possibilitando um movimento social pela Reforma Psiquiátrica, comprometendo a sociedade na construção de uma nova realidade para a loucura e a Psiquiatria (Amarante, 1996). Esse movimento promoveu diversas mudanças na assistência psiquiátrica aos portadores de transtornos mentais: a criação dos Centros de Atenção Psicossocial (CAPS) tipo I, II, III, Ad e $i^{2}$ e dos Serviços Residenciais Terapêuticos ${ }^{3}$; redução dos leitos psiquiátricos e tempo de internação; instalação de Unidades Psiquiátricas em Hospitais Gerais; centros de convivência e a inclusão da saúde mental na Atenção Primária.

Destaca-se ainda a lei 10.216 de 2001, maior conquista da luta antimanicomial iniciada no Brasil nos anos 1970, uma vez que defende a não internação prolongada e a redução das internações compulsórias, visando uma maior integração do paciente com sua família e com a sociedade, exigindo desta, portanto, responsabilidade e aceitação do portador de transtorno mental enquanto ser humano com seus direitos de cidadão. Algumas das ações mais atuais na área da saúde 
mental são derivadas das diretrizes estabelecidas pela lei Paulo Delgado, a qual explana: "O paciente há longo tempo hospitalizado ou para o qual se caracterize situação de grave dependência institucional, decorrente de seu quadro clínico ou de ausência de suporte social, será objeto de política específica de alta planejada e reabilitação psicossocial assistida" (Lei 10.216, 2001).

Dentre elas, o projeto denominado "Alta Assistida: uma prática dentro do processo de humanização do Hospital Dr. João Machado", foco deste estudo. Essa proposta foi criada por alguns técnicos e oficializada em outubro de 2005 e consiste em: 1) promover um contato com o paciente e sua família, após a alta; 2) direcionar o acompanhamento do portador de transtorno mental para alguma unidade de saúde ou CAPS que exista na região de seu domicílio; 3) diminuir a frequência de reinternaçôes de pacientes. Destina-se a "internos avaliados pela equipe interdisciplinar das suas enfermarias, que apresentem problemas graves de rejeição familiar, primeiro internamento, constantes reinternações e que precisem de encaminhamentos e resoluções específicas" (Souza e cols., 2006: 8).

No ano de 2007, buscou-se investigar de que maneira o projeto de AltaAssistida vinha se desenvolvendo na referida instituição. Interessava conhecer seu processo de implantação e funcionamento, bem como discutir acerca da inserção do Acompanhamento Terapêutico/AT como dispositivo potencializador daquilo que já vinha sendo feito em termos da saída dos pacientes. A preocupação era cuidar para que o projeto de Alta-Assistida não se restringisse a um trabalho meramente burocrático e assistencialista, resguardando as possibilidades terapêuticas que devem perpassar qualquer forma de assistência aos sujeitos com sofrimento mental, evitando uma descaracterização de seus princípios.

O acompanhamento terapêutico é uma forma de criar possibilidades reais de vida para os portadores de transtornos mentais, apostando no seu potencial criativo de se colocar no mundo. Busca reinserir o usuário na sociedade resguardando sua presença no meio social e familiar, configurando-se como uma prática cujo espaço clínico está nas ruas, tanto nas adjacências dos serviços de saúde quanto nos diferentes espaços sociais por onde o sujeito circular, ou seja, não apenas restrito à instituição.

Diante disso, foram estabelecidos os seguintes objetivos: conhecer como o projeto de Alta-Assistida vem sendo conduzido no HJM e avaliar a possibilidade de incorporação da prática do acompanhamento terapêutico. Delinear-se-á o acompanhamento de um caso a fim de avançar nas proposições a partir de uma experiência concreta. Nesse sentido, realizou-se uma investigação nos moldes da pesquisa-ação ${ }^{4}$, uma vez que o objetivo era atuar para uma transformação da realidade, repensar e modificar, juntamente com os profissionais de saúde, a 
forma como vem se dando a atenção à saúde mental no que se refere à alta de pacientes do HJM.

\section{Metodologia}

Partindo do objetivo imediato da pesquisa que era avaliar o estado atual em que se encontra a prática da Alta-Assistida no HJM e, em seguida, fazer com que o processo fosse realizado de uma maneira mais eficiente, bem como investigar a função do Acompanhamento Terapêutico e sua inserção como prática sistemática no processo de alta dos pacientes, o projeto de pesquisa foi conduzido da seguinte forma ${ }^{5}$ : o primeiro passo foi o de levantar dados em relação ao Projeto de AltaAssistida, avaliando os seguintes aspectos: processo de elaboração da proposta; equipe participante da elaboração e responsável pela condução; a quem se destina/público alvo; usuários que já participaram do processo. Foram também realizadas entrevistas com as profissionais responsáveis pela elaboração do Projeto de Alta-Assistida (uma psicóloga e uma assistente social), as quais, juntamente com uma equipe de estagiários, elaboraram o projeto por considerarem que a proposta poderia reduzir o número de reinternações no HJM.

\section{Resultados}

O levantamento dos dados foi realizado no primeiro trimestre de 2007 através de uma consulta ao livro de registro presente no setor de Serviço Social e em alguns prontuários de usuários. Verificamos que a primeira notificação de alta assistida consta em 14 de outubro de 2005 e, desde então, até o mês de julho de 2007, data de finalização da coleta, foram registrados 87 casos.

No livro há informaçôes sobre: nome do paciente; enfermaria em que estava internado; contato realizado e o encaminhamento; nome da pessoa de referência, familiar ou não; sobre a receptividade dos familiares, bem como do gestor de saúde, caso o usuário seja de outro município diferente da capital. Observamos que os registros foram predominantemente feitos por assistentes sociais e se referem, em geral, ao contato realizado com o gestor do município em que ele reside e com o serviço de assistência existente e para o qual o paciente foi encaminhado. Na maioria das vezes, a pessoa de referência era um familiar e a receptividade variou muito de caso para caso. Vale notar que há continuidade de informações em alguns casos, indicando se o paciente está ou não frequentando o serviço para o qual foi encaminhado, não se verificando regularidade quanto ao tempo para esse tipo de registro. Em relação aos pacientes de outros 
municípios, foi constatado que há informações únicas, como um telefonema, uma visita domiciliar realizada ou um contato com alguém do município (gestor ou um responsável por algum serviço de assistência), não havendo, no entanto, nenhum retorno a esses casos.

Identificamos através de leituras e observações do trabalho da equipe técnica que, em geral, os contatos realizados se restringem a uma ligação telefônica ou uma visita domiciliar, evidenciando uma falha no processo, pois não há como assegurar a continuidade do tratamento, uma vez que a equipe do HJM, que antes acompanhava o paciente, ao efetivar a alta hospitalar transfere a responsabilidade para outros serviços e familiares. Não há sistematização quanto ao retorno ao paciente, procurando, por exemplo, saber se ele está sendo assistido, se está frequentando um serviço substitutivo, se tem a medicação necessária e está fazendo o uso adequado, dentre outros aspectos que merecem atenção. Foi notado, nas entrevistas, que há uma priorização do primeiro contato após alta hospitalar para que os pacientes não saiam sem nenhuma assistência, nem encaminhamento. Apontam as dificuldades de se manter contato com os mesmos, pois são inúmeras as atribuições da equipe dentro do hospital, faltando tempo para se dedicar ao projeto. Em função disso, consideram inviável permanecer assistindo o paciente por muito tempo depois de sua saída do hospital, apesar de acreditarem ser esta uma prática fundamental enquanto "prevenção" de reinternação.

É válido frisar que o espaço de discussão sobre os rumos do projeto ocorre nas reuniões com a direção técnica e de maneira bastante informal, não havendo exigências ou controle em relação ao que está sendo realizado, cabendo à equipe de cada enfermaria se responsabilizar por seus pacientes e colocar o projeto em andamento. As suas elaboradoras enfatizaram ainda a necessidade de maiores discussões entre os diferentes profissionais que circulam nas enfermarias, já que muitos não têm conhecimento do projeto e de suas propostas.

Podemos dizer, em resumo, que apesar dos esforços empreendidos pela direção e pela equipe técnica, o projeto de Alta-Assistida enfrenta uma série de dificuldades, sendo as mais evidentes: desconhecimento da proposta pelo corpo técnico como um todo; falta de adesão de profissionais à proposta e consequentemente insuficiente número de pessoas para realizarem o trabalho; ausência de acompanhamento/seguimento cotidiano do que vem sendo feito, seja pela direção ou pela coordenação do projeto; insuficiência de recursos financeiros para o desenvolvimento de atividades externas; falta de articulação com a rede de serviços de saúde mental, tanto na capital quanto no interior do estado, no sentido de viabilizar o trânsito e acolhimento do usuário nos demais equipamentos sociais, não só de saúde mental, mas, por exemplo, o Programa de Saúde da Família e a rede básica 
de saúde e, por fim, ausência de um trabalho sistemático com as famílias que pudesse assegurar uma saída com corresponsabilização e cooperação. Todos esses aspectos indicam que o projeto é ainda algo restrito, dependente do interesse dos técnicos, não se configurando como uma política consolidada pela gestão do hospital, além de não estar tendo efeito sobre a reinternação sistemática, objetivo para o qual foi primordialmente pensado ${ }^{6}$. No primeiro trimestre de 2007 - quando foi realizado o levantamento de dados - foram registradas 435 internaçōes, das quais 270 eram reinternações, ou seja, $62,07 \%$ das internações correspondiam na verdade a reinternações no HJM.

A partir desse primeiro levantamento geral das condições de funcionamento da proposta de Alta-Assistida, decidimos formar uma equipe (médico, assistente social, psicólogo e pesquisadora) para acompanhar um caso. A ideia era inaugurar um outro modo de fazer a alta-assistida, trabalhando aspectos considerados fundamentais para que a proposta pudesse ser bem-sucedida. Além disso, a perspectiva era trabalhar com os recursos disponíveis, sem onerar a equipe em termos de horas de trabalho, e criar novas possibilidades de cuidado, superando, na medida do possível, os obstáculos já indicados, em especial aqueles que não estavam atrelados ao incremento de recursos financeiros, mas à cronificação das práticas. $\mathrm{O}$ caso foi selecionado segundo critérios de viabilidade para realização do Acompanhamento Terapêutico, a saber: paciente que residisse em Natal e preferencialmente de primeira internação.

\section{UM NOVO OLHAR É POSSÍVEL}

Eis a nossa acompanhada: Laura Silva ${ }^{7}$, cinquenta e um anos de idade, natural do interior do estado do Rio Grande do Norte. É viúva há oito anos, tem uma filha, Laísa, de nove anos de idade. Possui sete irmãos, quatro homens e três mulheres. Reside em Natal com a filha e um companheiro, João, de setenta anos de idade. Foi admitida, em primeira internação no HJM, em 30 de agosto de 2007, com avaliação médica de recusa de alimentação, indisposição generalizada, insônia, mutismo, humor depressivo, hipocinética, atenção e orientação comprometida, com diagnóstico de F 32.2 - Episódio depressivo sem sintomas psicóticos (CID-10). Sua acompanhante responsável era a irmã, Conceição Silva, que veio do interior para cuidar dela, permanecendo no HJM durante toda sua internação que durou aproximadamente um mês. A seguir, trazemos o diário com o registro dos nossos encontros, desde o período em que esteve internada até o pós-altahospitalar, a fim de orientar o leitor no desenvolvimento do acompanhamento terapêutico realizado. 


\section{DiÁRIO DE REGISTROS}

Até 01 de outubro de 2007, Laura permanece no Pronto Socorro desde sua admissão (30/08/07) até a saída, pois se encontrava desnutrida e com recusa de alimentação, o que exigia o uso da sonda para que se alimentasse. Sua irmã, Conceição, ficou todo o tempo no hospital, acompanhando-a, pois mora no interior e estava em Natal apenas para cuidar dela, segundo suas palavras. Os primeiros contatos foram breves e com pouco conteúdo, tendo em vista que Laura não estava falando, nem interagindo com ninguém. Continuei visitando-a em seu leito, até que um dia, ao perguntar-lhe como se sentia, ela respondeu "mais ou menos" (sic), e foi assim que iniciamos uma rápida conversa, quando ela concordou em tentar comer algo líquido. Solicitei à nutrição refeições pastosas e, desde então, ela passou a ingerir sopa, papa e iogurte.

Nesse período, quando o médico havia dado uma previsão para a alta hospitalar, falei sobre a proposta de um acompanhamento terapêutico para Laura, feito por mim. Sua irmã aceitou prontamente, já Laura disse que tanto fazia, mas combinamos que, caso ela saísse de alta e eu não estivesse no hospital, ela me ligaria e eu iria até sua casa para maiores esclarecimentos e para definirmos se iríamos ou não realizar esse acompanhamento, uma vez que considerei importante que ela concordasse e quisesse ser acompanhada, pois, corroborando Yagiu (2006), o acompanhamento terapêutico deve possibilitar ao sujeito a liberdade de fazer uma escolha, a fim de promover a saída da apatia e da existência habitada pela alienação, o acompanhado deve se conectar com algo que lhe faça sentido e que não lhe seja imposto de fora, inclusive o próprio acompanhamento terapêutico. Enfim, não poderia ser algo que apenas eu e Conceição desejássemos, mas havia sim a necessidade de que Laura, pelo menos, concordasse.

Quando Laura saiu de alta (02/10/07), Conceição me telefonou avisando que ficariam na casa de sua filha, Carla, por um ou dois dias, e iriam para o interior, pois precisaria resolver assuntos pendentes, já que estava perto de dois meses longe de casa. No dia seguinte, então, quarta-feira, fui até o apartamento de Carla, sobrinha de Laura, para nosso primeiro encontro extra-hospitalar, partindo do ponto de vista de que "a cidade e não mais o asilo, é o espaço em que a experiência da loucura [ou melhor, de qualquer transtorno mental] requer ser acompanhada" (Palombini, 2006: 117). No caminho, questionava-me sobre o que exatamente iria propor, o que conversaríamos, se seria realmente necessário um acompanhamento terapêutico para Laura, dentre tantos outros pensamentos que me vinham. Afinal, era a primeira vez que me colocava como acompanhante 
e por mais que eu tivesse lido e me aprofundado acerca dessa prática em nenhuma bibliografia havia algo específico ao caso que iria acompanhar, pois cada acompanhamento é único, Laura é única e nossos encontros também seriam únicos.

Laura era uma paciente de primeira internação e não tinha as sequelas de um histórico de internações em hospitais psiquiátricos. Foi a primeira vez que teve uma crise, o que não diminui a gravidade desta. Ela, segundo sua irmã, sempre chamou atenção por ser muito calada, com tendência ao isolamento, não tinha amigos, gostava, desde criança, de ficar só, além de que tinha uma obsessão por limpeza. Aos quarenta anos, teve seu primeiro relacionamento e se casou. Dois anos depois teve sua filha, Laísa, que quando tinha um ano de idade perdeu o pai num acidente de moto. Desde então, Laura passou a viver somente em função da filha e há três anos conheceu o seu atual companheiro de vida, Sr. João, com quem mora.

Chegando ao apartamento, deparei-me com praticamente um setting terapêutico montado na sala: havia duas poltronas, uma de frente para outra, com um centrinho no meio, estando numa delas Laura sentada e toda a família - a sobrinha, Carla, com as duas filhas e Conceição, a irmã - ficaria dentro de um quarto, enquanto eu "atenderia" Laura. Enfim, a família mostrou ter compreendido que eu, a acompanhante, seria uma espécie de psicóloga domiciliar e, logo, esclareci para Laura e Conceição que não seria essa a minha função, mas que este acompanhamento terapêutico objetivava identificar as necessidades de suporte assistencial de Laura e dos cuidadores visando evitar uma reinternação hospitalar. Além disso, interessava-me acompanhar Laura na descoberta de suas potencialidades, a fim de que saísse da posição incapacitante em que se encontrava. Destaco que, segundo Yagiu (2006), para a recuperação de um paciente há de se proporcionar uma aliança terapêutica do paciente com sua família, suporte social e integração ocupacional, o que também me orientava acerca da minha função naquele contexto.

Sentei ao lado de Laura e começamos a conversar. Era a primeira vez que ficávamos a sós e isso de certa forma possibilitou que ela falasse mais sobre si, ou melhor, que nos conhecêssemos. Ela, ainda bastante debilitada com expressão facial e postura corporal denotando humor deprimido, um olhar fixo e com tremores nas mãos, limitava-se inicialmente a responder algumas perguntas, mas com o tempo foi ficando mais à vontade. Questionei se ela tinha compreendido o propósito da minha presença e o que ela achava. Laura colocou que achava estranho e esquisito e que por ela tanto fazia (a realização do acompanhamento terapêutico) e acrescentou "Tanto faz viver ou morrer" (sic). Discorreu sobre sua história, que começou a se sentir triste há mais ou menos um ano, mas não sabe 
dizer por que e que saía andando nas ruas, pois não conseguia ficar em casa. Preocupava-se com "as coisas de casa” (sic) e não quis falar sobre elas. Disse que sua relação com a filha era "normal, quando ela quer ser boa é, mas também quando não quer...” (sic).

Depois de conversarmos bastante, reiterei a proposta do acompanhamento terapêutico, afirmando que iríamos circular pela cidade e ela prontamente disse "eu não gosto de sair de casa pra nada” (sic). Nesse momento, fui surpreendida com uma recusa diante do princípio básico que rege o acompanhamento terapêutico, isto é, a passagem do espaço fechado do hospital para o território aberto da cidade (Palombini, 2006), já que é aí, nos diferentes espaços sociais do território, que se dão os encontros entre acompanhante e acompanhado. Tal acontecimento foi de fundamental importância para a compreensão de que devemos atentar em nosso trabalho para a singularidade de cada um, sem lhe impor nossos desejos ou expectativas e assim propiciar o surgimento de elementos inovadores e criativos. Dessa forma, Laura me propiciou a reflexão de que não há condutas, regras ou técnicas a serem seguidas quando se lida com pessoas, há sim que se priorizar a singularidade do individual no universo do coletivo. $\mathrm{O}$ acompanhamento terapêutico deve se afastar dos processos adaptativos e funcionais, dado que é uma intervenção que se dá nas criações e vivências que podem surgir nos encontros, buscando a potência de cada um (Muylaert, 2006). A própria autora, Palombini (2004), fala da criação de espaços que possibilitem ensaios, inscriçôes singulares a serem construídas sem preocupação com o certo ou o errado e aponta também que o AT geralmente se inicia no espaço fechado do quarto, ainda que tenha a cidade como seu horizonte.

Próximo ao final da conversa perguntei sobre a viagem ao interior e ela afirmou que não queria ir, mas que compreendia o fato de a irmã ter que ir e, como não podia ficar só, iria também, só não gostaria de demorar. Depois, sentiu-se cansada e disse que queria se deitar. Combinamos que ela me ligaria assim que voltasse para Natal. Sua irmã, Conceição, pediu orientações acerca da medicação. Esclareci que a receita era do médico e, portanto, caberia a ele suspender ou não qualquer medicação. Responsabilizei-me em entrar em contato com o psiquiatra de referência para orientá-la. No final, perguntei pela viagem e ela disse que estava querendo ficar o mês lá. Na ocasião, então, falei que Laura preferia ficar na casa dela e que seria bom que elas retornassem logo que possível. Conceição prontamente afirma: "Ela tá fora de si e gente louca assim não tem querer não" (sic). Enfatizo que, apesar de ela estar doente, ela possui vontade e precisa ser levada em conta, que, ao contrário do que ela está pensando, é de fundamental importância 
que se dê relevância à vontade de Laura, às suas escolhas, independente do transtorno mental que estiver apresentando.

Palombini (2006) problematiza a passagem do espaço fechado do hospital para o território aberto da cidade, questionando se isso seria suficiente para subverter as relações de poder instituídas desde a origem do manicômio. E essa reflexão é cabível dentro desse contexto, ou seja, as relaçôes de poder provindas da institucionalização da loucura e não somente da desospitalização em que o louco, ou aquele que possui transtorno mental, é relegado à insignificância ou coisificação, não tendo voz, nem vez, e isso precisa ser fonte de alerta por parte do acompanhante terapêutico, devendo este estar constantemente às voltas com o desafio da desinstitucionalização, nas relações que for estabelecendo nos diferentes espaços sociais por onde transita.

Conceição se mostra compreensiva e se compromete em voltar com Laura assim que possível; combinamos que eu esperaria pelo contato. Em 04 de outubro viajam e retornam duas semanas depois para a casa de Laura. Após dois dias, Carla, filha de Conceição, telefonou-me avisando que tinham chegado. Liguei para a casa de Laura, Laísa atendeu e disse que eu queria falar com Laura; Conceição quis atender, mas a própria Laísa enfatizou que era com sua mãe que eu queria falar. Esse pequeno acontecimento, o fato de mais uma vez a irmã se colocar à frente de Laura, denota o quanto está arraigada essa concepção de incapaz que é associada ao paciente com transtorno mental. Lerner (2006) explana acerca da prática do acompanhamento terapêutico e destaca que esta, ao ser legitimada, pode fazer surgir um novo discurso que funde e sustente novas relações entre a clientela de uma instituição e seus agentes (profissionais de saúde), podendo retirar o sujeito com transtorno mental do lugar que o caracteriza de insuficiência ou incompetência: "Diferentes marcas discursivas levam a diferentes formas de ocupação de lugares, ou seja, diferentes formas de exercício de poder" (Lerner, 2006: 25).

Ao telefone, Laura se apresentou bem diferente, estava falante, mostrando-se animada e dizendo com ênfase que estava bem, fazendo de tudo dentro de casa: "agora mesmo acabei de lavar uma pilha de roupa" ( $s i c$ ). Falou que a viagem tinha sido boa e que sua irmã já podia ir pra casa dela, ela preferia assim. Conceição pede para falar comigo e pergunta se deve ou não voltar pra casa, digo que elas podem decidir isso e se Laura está bem, está sendo acompanhada, está tomando a medicação e prefere ficar apenas com sua filha e seu companheiro em casa, ela poderia voltar. Em 24 de outubro, entrei em contato com Laura por telefone e combinamos de nos encontrar na sexta-feira dia 26 de outubro. No entanto, ela telefonou desmarcando, pois iria resolver umas coisas. Nessa ocasião eu havia repensado a proposta da equipe que era composta por profissionais do HJM e 
concluí que ao pensar o acompanhamento terapêutico como uma prática que promove a desinstitucionalização e defende a circulação do acompanhante pelos diversos espaços sociais, inclusive no que diz respeito a sua assistência, não haveria sentido em manter a equipe do HJM como referência para Laura, o que a prenderia ao hospital psiquiátrico. Em vez disso, resolvi inseri-la na rede de assistência de sua comunidade, o que é corroborado por Palombini (2006), que enfatiza que o acompanhamento terapêutico requer uma nova forma de ação, tanto pelo acompanhante, quanto pela equipe do hospital, e que do ponto de vista político destaca-se que, ao circular pela cidade, nos serviços oferecidos à assistência e nos diversos espaços sociais, o acompanhante vivencia o próprio processo da Reforma Psiquiátrica em seu território, analisando o funcionamento da rede e a forma como a comunidade responde à desinstitucionalização. Partindo dessa nova reflexão, informei-me acerca dos serviços disponíveis próximos à residência de Laura e combinei com ela de juntas irmos conhecê-los.

No dia 01 de novembro fui até a casa de Laura. Ela me esperava junto com a filha e seu companheiro na calçada, para facilitar minha localização. Conheci sua filha que, logo que me viu, disse "Vou passear com vocês" (sic). Laura perguntou se ela poderia ir e eu disse que sim. Ela me mostrou sua casa, a qual é muito organizada, limpa e agradável, destoando da vizinhança. Estava com ótima aparência, falante e perguntou se eu gostaria de conversar um pouco antes de irmos e foi logo se sentando na sala. Então sentei-me também e ela de imediato começou a falar ininterruptamente, disse que ficou sabendo que o psicólogo ajuda quando escuta o paciente falar de sua vida e por isso tinha que contar que a filha não aceita o Sr. João como seu companheiro de vida e que sabe que Laísa sofre porque não conheceu o pai, que faleceu num acidente de moto, quando ela tinha um ano de idade. Escutei e esclareci que, se ela gostaria de falar mais sobre as questões que a deixavam ansiosa e preocupada, poderia ser atendida pela psicóloga do Posto de Saúde da área que iríamos conhecer. Lembrei que o acompanhamento teria um tempo limitado, então iria ajudá-la a se inserir nos serviços de saúde que precisasse e depois ela seguiria com outras retaguardas.

Em seguida, saímos eu, Laura e sua filha com destino ao Posto de Saúde de Igapó. Como não tenho costume de andar pela Zona Norte, região onde ela mora, tive dificuldade de chegar ao local, o que de certa forma foi bom para Laura, posto que disse que adorava andar de carro e que apesar de morar lá há muito tempo não tinha percebido como a Zona Norte estava grande, com muita gente. Era final de tarde e ela se espantou com o número de pessoas na rua, já que nesse horário ela não saía de casa, pois tinha de preparar o jantar. E nesse percurso pudemos vivenciar o seu território de outra forma, com outros olhares e possibilidades, passar a sair à 
noite, já que para ela estava sendo tão bom, sem falar que sua filha também estava adorando o passeio de carro e disse à mãe que, quando não puderem ir de carro, vão de ônibus, que também é bom de passear. Chegamos ao Posto de Saúde. Ela nunca havia ido lá e gostou do aspecto. Apresentei a psicóloga a Laura e elas agendaram o primeiro atendimento. Informamo-nos sobre os serviços que são disponíveis lá e voltamos para casa, pois ela já estava preocupada com o jantar do companheiro. Laura agradeceu por ter-lhe mostrado o Posto de Saúde e afirmou que agora se sentia mais segura, pois sabia a quem podia recorrer caso não se sentisse bem.

Seus medicamentos estavam próximos de acabar e ela saiu do HJM sem nenhum retorno ao médico psiquiatra marcado. Então, coloquei que precisávamos providenciar isso e Laura me disse que queria ficar com o médico que a tinha atendido. Respeitando o vínculo que ela estabeleceu com seu médico, comprometi-me de agendar com ele uma consulta para ela. Em 05 de novembro entrei em contato com seu psiquiatra e ele informou que atendia no Centro de Saúde da Cidade da Esperança e que poderia acompanhá-la. Agendei a consulta para o dia 14/11/2007. Laura colocou que poderia ir sozinha. No dia seguinte, Laura me telefonou dizendo que tinha ido para as consultas da psicóloga e do psiquiatra. Falou que estava se sentindo ótima e que tinha diminuído a quantidade de remédios. No momento, aproveitei para encerrar o acompanhamento terapêutico, colocando-me à disposição para caso ela precisasse de alguma coisa. É importante ressaltar que não obstante o AT ter sido encerrado, para me certificar de que ela estava prosseguindo bem e conseguindo de fato "caminhar" sozinha, fiz alguns contatos por telefone durante certo período, o que me deixou tranquila e satisfeita em relação ao AT realizado, uma vez que Laura continuou se mostrando bem e segura diante de seu tratamento e sua vida.

\section{Discussão}

A experiência descrita nos leva a entender que na prática do acompanhamento terapêutico há elementos importantes que devem perpassar esse dispositivo clínico-político: a presença dos princípios da Reforma Psiquiátrica nos discursos, leis e medidas administrativas nos diferentes atores desse processo (governo, serviço, profissionais, comunidade); um espaço de atuação externo aos muros do hospital; um campo de conhecimentos amplo que não se restrinja a um único saber; e a disponibilidade ao encontro pelo acompanhante e pelo acompanhado para experimentar o novo e o inusitado (Palombini, 2006). Consideramos, então, o acompanhamento terapêutico um dispositivo importante que pode transformar 
a estratégia do Projeto Alta-Assistida do HJM, propiciando uma assistência mais eficaz ao portador de transtorno mental e a seus familiares, e com potencial de promover um contato mais próximo entre o profissional de saúde (acompanhante) e o usuário, assegurando um acompanhamento ininterrupto e de melhor qualidade.

O arcabouço teórico que sustenta a clínica do AT encontra-se em fase de franca expansão. Há muitas definições e perspectivas de compreensão do AT. Aqui se elege o pensamento de Guattari (1990) para conceituar a prática do AT e nortear essa investigação, comentado por Dimenstein e cols. (2007) e por Araújo (2006):

O AT é uma prática que se dá em agenciamentos que vão da subjetividade humana aos espaços sociais, dos espaços sociais ao meio ambiente, do meio ambiente à subjetividade. Tudo isso com a força da instantaneidade. Não é uma clínica unicamente do indivíduo problemático/doente/necessitado, mas uma vivificação da subjetividade na cena/cenário público e da própria cena/ cenário público, se dando em um registro ecosófico (Araújo, 2006: 31).

O acompanhamento terapêutico é, pois, uma estratégia fundamental no processo da Reforma Psiquiátrica e de inserção de portadores de transtornos mentais na vida extramanicomial. É uma modalidade de atenção que utiliza o espaço público e a cidade como espaço onde processa sua ação na medida em que visa à circulação do usuário na cotidianeidade, investindo em estratégias de enlace social. Não é uma prática restrita a um grupo específico de técnicos, podendo ser exercida por diferentes pessoas que, após treinamento adequado - conhecimento do processo da Reforma Psiquiátrica, seus conceitos chaves, como desinstitucionalização, equidade, integralidade, acolhimento, vínculo e responsabilização; aproximação com a prática do AT, situando-a historicamente e contextualizando seu surgimento; aprofundamento em relação à condução clínica do AT sob diferentes aspectos, a partir de temas como transferência e direção do tratamento; enfim, uma preparação para fornecer ao paciente uma possibilidade de escuta -, podem exercer a função de acompanhantes terapêuticos.

O dispositivo do AT insere-se para além do espaço estrito dos estabelecimentos de saúde, realizando uma "clínica sem muros", na qual o setting terapêutico se configura a cada incursão no espaço urbano ${ }^{8}$. O trabalho do AT se situa num contexto contemporâneo de produção de subjetividade que segrega todo modo de subjetivação diferente do padrão, do considerado "normal" - portanto, o do portador de transtorno mental, resultando no enfraquecimento de sua potência criadora de novos modos de existir. A ética deve, então, embasar o acompanhamento terapêutico, impedindo o enquadramento à hegemonia de qualquer mo- 
delo teórico e prático, comprometendo-se em encontrar vias criadoras para cada sujeito que constituirá seu novo e singular mundo.

Partimos do princípio de que discutir o acompanhamento terapêutico é pensar sobre a clínica na atualidade e seu compromisso com uma política cotidiana de apreço à vida. Trata-se, portanto, da instauração de processos micropolíticos cuja dimensão ética é evidente, pois "o cuidado com a existência, própria e dos outros, passa a ser orientado pelo desejo de reorganização de relaçôes sociais caracterizadas pela multiplicidade de forças e recursos, acrescido do aumento na apreciação dos diferentes modos de ser sujeito" (Noronha, 2005: 5).

Nos últimos tempos vem se debatendo muito a clínica, principalmente a partir dos movimentos advindos da luta antimanicomial e do processo de reforma sanitária. Todo um questionamento voltado para os seus limites, suas medidas normativas, suas estratégias de poder, enfim, sobre como pensar um lugar fora desse círculo de fixação e conservadorismo tem sido empreendido. Sabe-se que o que é hegemônico no campo psi é pensar a clínica como uma prática que está ancorada na ideia de sofrimento psíquico individual, que traz em si uma intenção generalizante, uma ambição de universalidade, e a política como sendo dirigida a coletivos, a conflitos na organização da sociedade, havendo uma nítida desconexão entre tais esferas.

Pensar a clínica enquanto prática não está atrelado à mera questão de manejo de técnicas, mas se trata de uma atitude de intervenção, de um modo de pensar. Essa atitude pode tender à conservação de modos instituídos (tendência passiva) ou a uma perspectiva ativa de produção de diferença, de experimentações. Nesse sentido, a função por excelência da clínica seria a de acompanhar movimentos, metamorfoses subjetivas, paisagens que vão se processando cotidianamente na vida, proporcionando um meio criador para encontros e composiçōes. É menos artefato e mais atitude, menos método e mais invenção, menos certeza e mais tateio, menos direcional e mais experimental, clínica que acontece no mundo, que resiste aos localizacionismos já que extrapola limites de setting, sem predeterminismos, cujo rigor tem a ver mais com sua capacidade de ativação, de fazer conexôes, de se metamorfosear do que com o domínio de ferramentas teóricas/técnicas de forma adequada. Lancetti (2006) chama isso de clínica peripatética, cartográfica, clínica insólita, autopoiética; Baremblitt (1995) diz que a clínica é o espaço epistemológico da criação, da inventiva, lugar da espontaneidade, do inesperado; enfim, independente do nome, a clínica definitivamente é uma experiência com afetos.

Foi pautada nessa dimensão política da clínica que se produziu a proposta desse acompanhamento terapêutico, pois muito mais que se ater ao "sofrimento 
psíquico individual" de Laura, enfatizou-se, sim, a sua inserção no entorno, na rede de assistência de sua comunidade, na sua circulação pela cidade e na possibilidade de produção de novos modos de vida. Deste modo, se clínica tem a ver com afetos e política com fabricação de modos de existência, é fácil pensar a clínica como uma prática política ou micropolítica, engajada em aberturas afetivas para a produção de territórios subjetivos. A clínica opera uma política que é subjetiva. Isso quer dizer que quanto mais aderidos à lógica subjetiva hegemônica menos sensíveis às capturas produzidas no cotidiano e menos potente se é na produção de um espaço favorável às transformaçôes, ou seja, mais se estabelece a clínica das normatizações, da uniformização, do instituído, do desempenho, das identidades, do compromisso social com a reprodução e com a exclusão da diferença.

Concebemos, portanto, que toda clínica é política, pois é um exercício de poderes, e a clínica do acompanhamento terapêutico enquanto dimensão política deve operar apostando na presença de uma resistência à captura, mantendo a conflitualidade e seguindo os caminhos desviantes da invenção, para que não se deixe descansar à sombra dos poderes instituídos (Palombini, 2006). Dessa maneira, é digno de nota que o acompanhamento terapêutico seja fundamental para os usuários que compóem o público alvo do Projeto de Alta-Assistida, posto que o acompanhamento terapêutico deve atuar também no restabelecimento de ligações sociais, na manutenção do cotidiano e na criação de outros espaços vitais e possíveis para o sujeito em sofrimento, por meio do encontro singular entre o acompanhante terapêutico, PTM e/ou seus familiares, novas relaçóes podem ser descobertas, experimentadas e incluídas pelos acompanhados, ampliando seu universo existencial que, em geral, é bastante restrito.

\section{REFERÊNCIAS BIBLIOGRÁFICAS}

Araújo, F. R. (2006). Um passeio esquizo pelo acompanhamento terapêutico: dos especialismos à política da amizade. Rio de Janeiro: sem editora.

Amarante, P. (1996). O homem e a serpente: outras histórias para a loucura e a psiquiatria. Rio de Janeiro: Editora Fiocruz.

Baremblitt, G. (1995). Por una nueva clínica para el poliverso "psy”. SaúdeLoucura, v. 5, 11-30.

Dimenstein, M.; Cabral, C.; Severo, A. K.; Brito, M. \& Alverga, A. R. (2007). Saberes e fazeres de agentes comunitários de saúde frente à experiência da loucura. Pesquisas e Práticas Psicossociais, v. 2, 87-95. 
Guattari, F. (1990). As três ecologias. Campinas: Papirus.

Lancetti, A. (2006). Clínica peripatética. São Paulo: Hucitec.

Lei 10.216. (2001). Disponível em <http://www.paulodelgado.com.br/leisaprovadas/ lei10216.htm>. Acessado em 27/11/2006.

Lerner, R. (2006). Matriz discursiva da contratransferência: discussão ética acerca do acompanhamento terapêutico e de instituições de saúde mental. Psychê, Revista de Psicanálise, ano X, 18, 21-28.

Machado, K. (2005). Como anda a Reforma Psiquiátrica? Comunicação e Saúde, 38, 1119.

Muylaert, M. A. (2006). AT como dispositivo clínico: uma perspectiva da esquizoanálise. Psychê, Revista de Psicanálise, ano X, 18, 109-114.

Noronha, P. (2005). Micropolíticas da alegria na clínica coletiva na saúde mental pública. Texto apresentado no Io Encontro da ULAPSI, São Paulo.

Palombini, A. L. (2004). Acompanhamento terapêutico na rede pública: a clínica em movimento. Porto Alegre: Editora da UFRGS.

. (2006). Acompanhamento terapêutico: dispositivo clínico-político. Psychê, Revista de Psicanálise, ano X, 18, 115-127.

Souza, L.; Souza, L. P.; Lima, N. \& Souza, H. (2006). Alta Assistida: uma prática dentro do processo de humanização do Hospital Dr. João Machado. Natal: sem editora.

Thiollent, M. (1998). Metodologia da pesquisa-ação. São Paulo: Editora Cortez.

Yagiu, H. (2006). Projetos no A.T.: apontamentos para elaboração. Em Gomes, R. (org.). Textos, texturas e tessituras no A.T. (pp. 157-172). São Paulo: Instituto A Casa / Editora Hucitec.

\section{Notas}

1 Este trabalho é fruto de uma experiência de estágio curricular realizado em 2007 pela primeira autora e supervisionado pela segunda.

2 Essas diferentes denominações referem-se ao tipo de cobertura que é ofertada e ao tipo de demanda atendida, como é o caso do atendimento a crianças e adolescentes e a usuários de álcool e outras drogas.

3 "Moradias inseridas na comunidade destinadas a pacientes com transtornos mentais egressos de internaçôes psiquiátricas de longa permanência com dificuldade de integração familiar, moradia e reinserção social" (Machado, 2005: 38).

4 Este é um tipo de pesquisa social com base empírica que é concebida e realizada em estreita associação com uma ação, ou com a resolução de um problema coletivo, e na qual os pesqui- 
sadores e participantes representativos da situação ou do problema estão envolvidos de modo cooperativo ou participativo (Thiollent, 1998).

5 Depois de obtida autorização da direção técnica do HJM.

${ }^{6}$ Esses aspectos estão sendo alvo de uma nova investigação que está em curso com o propósito de aprofundar tal análise e gerar estratégias de enfrentamento juntamente com o corpo técnico do HJM.

7 Nomes fictícios.

8 Citação encontrada nos folderes de divulgação dos colóquios realizados em Porto Alegre (2005) e em Niterói (2006), intitulados "Colóquio em dois movimentos: de Porto Alegre a Niterói - Acompanhamento Terapêutico e Políticas Públicas de Saúde”.

Recebido em 02 de janeiro de 2008 Aceito para publicação em 06 de maio de 2008 